\title{
THERE IS No (SUI GENERIS) NORM OF ASSERTION
}

There are norms on action and norms on assertion. That is, there are things we should and shouldn't do, and things we should and shouldn't say. How do these two kinds of norm relate? Are norms on assertion reducible to norms on action? Many philosophers think they are not. These philosophers claim there is a sui generis norm specific to assertion, a norm which is also often claimed to be constitutive of assertion. Both claims, I argue, should be rejected. The phenomenon claimed to support them - the intuitive wrongness of certain assertions - does not in fact support them. Because assertion is an action, the wrongness of assertions can be explained purely by norms on action. And the specifically epistemic wrongness an assertion norm is typically supposed to explain can be explained by an uncontroversial norm on action: one shouldn't act on epistemically faulty beliefs. No additional sui generis norm on assertion is needed.

\section{Introduction}

My target is the claim that there is some sui generis norm constitutive of assertion. This claim was popularized by Timothy Williamson, but it's made or assumed by many writing in the literature following him. Williamson makes two claims:

SUI GENERIS NORM: There is some sui generis (and constitutive) norm on assertion (1996, pp. 489ff.).

KNOWLEDGE NORM: The specific sui generis norm on assertion is a knowledge norm, i.e. one ought not to assert that $\mathrm{p}$ unless one knows that $\mathrm{p}$ (1996, pp. 502ff.).

I will reject SUI GENERIS NORM. And since SUI GENERIS NORM is entailed by KNOWLEDGE NORM, this also amounts to rejecting KNOWLEDGE NORM.

We should note that the 'sui generis' and 'constitutive' aspects of SUI GENERIS NORM are distinct and separable. A norm on assertion is sui generis if it is not reducible to other norms assertion is subject to, such as moral, prudential, or cooperative norms. ${ }^{1}$ A norm on assertion is constitutive if part of what it is to make an assertion is to be subject to a particular norm. Defending a constitutive norm on assertion is, on Williamson's analogy, to claim that asserting is like making a move in a game. For example, part of what it is to make a chess move is to be subject to a norm that one may only move a bishop diagonally. A

\footnotetext{
${ }^{1}$ Williamson understands the norm he defends to be sui generis, as I've defined it, as he distinguishes it from norms of 'relevance, good phrasing, and politeness', which he claims 'are just applications of more general cognitive or social norms to the specific act of assertion', and he states that, on the view he is defending, 'not all norms for assertion derive from more general norms' (1996, p. 489).
} 
constitutive norm on assertion is supposed to function like such constitutive norms involved in playing games.

Williamson defends both SUI GENERIS NORM and KNOWLEDGE NORM. He argues at length in support of KNOWLEDGE NORM; little to no direct argument is given for SUI GENERIS NORM. ${ }^{2}$ Williamson argues that KNOWLEDGE NORM explains the intuitive wrongness of certain assertions. The resulting literature has largely agreed that the phenomena he appeals to are appropriately explained by some sui generis norm on assertion. The debate has largely been about what that norm prescribes, i.e. whether it's a KNOWLEDGE NORM or some alternative, such as:

TRUTH NORM: One ought not to assert that p unless $\mathrm{p}$ is true. (Weiner, 2005; Whiting, 2013)

JUSTIFICATION NORM: One ought not to assert that $\mathrm{p}$ unless one is justified in believing that p. (Douven, 2006; Kvanvig, 2009)

These other norms are claimed, contra Williamson, to better explain the intuitive wrongness of assertions.

I will dispute the key shared assumption that the intuitive wrongness of assertions is the kind of phenomenon best explained by a sui generis norm of assertion. I'll argue, contra Williamson and his critics, that the intuitive wrongness of assertions is just as well explained, if not better explained, by norms on action. This means independent argument for SUI GENERIS NORM is required before the intuitive wrongness of assertions provides any support for a specific sui generis norm on assertion.

I'll start, in §2, by summarising Williamson's arguments for KNOWLEDGE NORM. In $\S 3$, I'll outline the strategy of explaining the wrongness of assertions without appeal to a sui generis norm, which I'll call the 'no-norm-of-assertion strategy'. In $\S 4$, I'll discuss three versions of the no-norm-of-assertion strategy which don't work. I'll then give my own version in $\S 5$, which appeals to epistemic norms on action, and I'll answer objections to it in $\S 6$.

\section{Williamson's arguments for knowledge norm}

Williamson claims knowledge norm best explains:

\footnotetext{
${ }^{2}$ It's not clear that Williamson takes himself to give arguments for SUI GENERIS NORM specifically. He briefly suggests that if there weren't some sui generis norm constitutive of assertion 'nothing would differentiate it from other speech acts' (1996, p. 489), but this claim is not defended in any depth. Also, he describes his method of arguing for a norm on assertion as 'supposing that [assertion] has such rules, in order to see where the hypothesis leads and what it explains' (1996, p. 490). Therefore, Williamson is probably best understood as viewing SUI GENERIS NORM and KNOWLEDGE NORM as jointly supported by the fact that they can explain the intuitive inappropriateness of assertions.
} 
(a) The wrongness of asserting lottery propositions, e.g. 'My ticket didn't win'.

(b) The wrongness of asserting a kind of Moore-paradoxical proposition, those of the form 'p, but I don't know that p'.

(c) Why we respond to assertions by saying 'How do you know that?'.

In each case, Williamson claims alternative norms on assertion - in particular, a truth norm - cannot explain the phenomena. Let's briefly take each case in turn.

First, consider lottery propositions. Say you have a ticket in a very large lottery. The draw has taken place and your ticket has not won, but the results haven't been released yet. You think (quite rightly) that, given the number of tickets, your ticket is highly likely to not be the winning ticket. Williamson claims it is intuitively wrong for you to assert 'My ticket did not win'. This wrongness, Williamson claims, cannot be explained by a truth norm, because your assertion is true, and moreover you have very strong (albeit statistical) evidence that it is true (1996, pp. 498-501). A knowledge norm, however, can explain this wrongness because one plausibly cannot know that $\mathrm{p}$ if one has merely statistical evidence in favour of $\mathrm{p}$ (Williamson, 1996, pp. 502-4).

Second, consider propositions of the form 'p, but I don't know that p'. Williamson claims it's intuitively wrong to assert any such proposition. And this again can be explained by a knowledge norm, because such propositions cannot be known. Knowing one would involve knowing both conjuncts, and knowing the first conjunct makes the second conjunct false and, therefore, by the factivity of knowledge, not known. Given this, a knowledge norm explains why it's inevitably wrong to assert it (Williamson, 1996, p. 506). A truth norm on the other hand cannot do this, because propositions of the form 'p, but I don't know that p' can be true. Moreover, one can often have good evidence (though evidence short of knowledge) that such propositions are true (Williamson, 1996, p. 507). In fact, an example of a case in which someone has such evidence is the lottery case we've just covered.

Before moving on, we should note the wrongness or impropriety under discussion is understood to be distinctively epistemic, and distinct from non-epistemic ways in which assertions can be improper, e.g. by being tactless, deceptive, etc. Williamson doesn't explicitly say the wrongness in question is epistemic, but it's clear is he understands it to be. For example, Williamson claims his account explains why asserting $\mathrm{p}$ represents one as knowing $\mathrm{p}$, because representing oneself in this way requires the 'epistemic authority' to do so: 'In doing anything for which authority is required (for example, issuing orders), one represents oneself as having the authority to do it. To have the (epistemic) authority to assert that $\mathrm{P}$ is to know that $\mathrm{P}^{\prime}$ (Williamson, 1996, p. 505, fn. 9).

Williamson's third argument is that a knowledge norm best explains why a standard response to assertion is 'How do you know that?'. This response presupposes the speaker knows what they said. What makes this presupposition legitimate can only be easily explained, Williamson claims, by a knowledge norm, because only such a norm would give us an expectation that speakers know what they assert (1996, pp. 506-7). 
Whilst more can be said about these arguments, all I have intended to do is illustrate the nature of the phenomenon Williamson appeals to, the intuitive wrongness of assertions and how we challenge them. This is because I'm going to argue that this is not the kind of phenomenon that requires a sui generis norm on assertion to explain it.

\section{The no-norm-on-assertion strategy}

We can show that the wrongness of the assertions Williamson discusses does not support SUI GENERIS NORM if that wrongness can be explained the combination of:

(a) Psychological aspects of assertion, which make it the speech act that it is.

(b) General norms not specific to assertion.

Explaining the wrongness of assertions in terms of these factors is what I call the 'no-normon-assertion strategy'.

In defending this strategy, I'll initially grant that the assertions Williamson discusses are indeed 'wrong', but I'll do this to show this wrongness doesn't support a sui generis norm on assertion. My argument still goes through if you don't share Williamson's intuitions, or if you don't think they shouldn't be explained by reference to knowledge. My claim is that whatever side we take in this first-order debate, it doesn't support a sui generis norm constitutive of assertion.

That describes the no-norm-of-assertion strategy in the abstract. Before I outline my version of it, I'll discuss three others that don't succeed. ${ }^{3}$ But I'll first make two caveats.

\section{1. $1^{\text {st }}$ Caveat: Only sincere assertions}

I will only explain why sincere assertions can be criticized in the distinctively epistemic fashion discussed in the norm-of-assertion literature. I won't attempt to explain, for example, why insincerely asserting a lottery proposition is wrong in a distinctively epistemic manner. Any wrongness in such an assertion can be explained in other terms, such as in terms of the wrongness of deception.

One might object to this for a couple of reasons. Firstly, one might claim it is ad hoc. Secondly, one might claim that a unified treatment of sincere and insincere assertions should be preferred on grounds of simplicity. After I've outlined my account, I'll answer both of these objections. There is, I will argue, no good reason to think the epistemic wrongness the norm-of-assertion literature discusses is common to both sincere and

\footnotetext{
${ }^{3}$ I won't discuss Cappelen's arguments against SUI GENERIS NORM (2011, sec. 4) because he doesn't give a version of the no-norm-of-assertion strategy. Rather than explaining the inappropriateness of assertions through other means, he raises doubts about whether the inappropriateness of assertions is a suitably stable phenomenon to be explained by a specific norm on assertion.
} 
insincere assertions. In fact, there is reason to deny this, because epistemic criticism looks out of place with insincere assertions, so the fact that my account treats insincere assertions differently is actually a point in its favour.

\section{2. $2^{\text {nd }}$ Caveat: The results for the norm-on-assertion literature}

I'll secondly note what my conclusion would mean for the contemporary debate about the norm of assertion. This debate has largely assumed the claim that I will be arguing against, i.e. that there is some sui generis and constitutive norm on assertion. The debate has been about what that norm prescribes. If I'm right, then the participants in this debate have been proceeding under a false assumption. They have been arguing about what the sui generis norm on assertion prescribes when there is no such norm.

However, the key moves in the debate can be transposed to terms consistent with my conclusion. It's uncontroversial that there is some epistemic norm on action, i.e. that one shouldn't act on epistemically faulty beliefs. The norm-of-assertion debate can and should instead be viewed as unpacking the sense of 'epistemically faulty' in that norm. Viewed like this, most of the moves in the dialectic can remain.

This is illustrated by the fact that uses of a norm on assertion often don't rely on that norm being sui generis and constitutive. Jessica Brown and Herman Cappelen make this point in reference to 'shifty' views of the semantics of 'knows', such as epistemic contextualism ('knows' depends on the context of attribution) and epistemic impurism ('knows' depends on how much is at stake). Each of these views have been defended on the grounds that the standards of appropriate assertion shift depending on the context (DeRose, 2002) and on the stakes (Hawthorne, 2004, sec. 2.4). Brown and Cappelen point out, quite correctly, that a knowledge norm can support these shifty views independently of whether it is sui generis and constitutive (2011, p. 11), and the same is the case if the standards of appropriate assertion stem from norms on action.

My account thus allows us to retain the plausible idea that how we challenge and criticize assertions is evidence for epistemological theorizing, but gives that idea a theoretical foundation even those sceptical of a sui generis norm constitutive of assertion can be happy with.

\section{Three versions of the no-norm-of-assertion strategy that don't work}

Before I defend my version of the no-norm-of-assertion strategy, I'll first rule out three other versions. Although they don't work, the reasons why they fail point towards a version of the no-norm-of-assertion strategy that will work.

\subsection{Pagin: norms on assertion are reducible to moral norms}

Peter Pagin claims that 'any linguistic phenomenon that can be explained by appeal to a knowledge norm can be equally well explained by appeal to the view that 
asserters represent themselves as knowing what they say' when this is combined with nonassertion-specific norms (2016, p. 203). This means that the wrongness of asserting, say, a lottery proposition can be explained by 'the general moral norm that it is wrong to mislead hearers, e.g. by representing oneself as having knowledge' (Pagin, 2016, p. 203).

This is an instance of the no-norm-of assertion strategy because it attempts to explain the wrongness of assertions by appealing to:

(a) A psychological feature of assertion: If A asserts that $\mathrm{p}, \mathrm{A}$ represents themselves as knowing that $\mathrm{p}$.

(b) A non-assertion-specific norm: One ought not deceive.

This version won't work, however, because the wrongness of asserting a lottery proposition is thought, by both Williamson and other participants in the debate, to be a distinctively epistemic wrongness. A moral norm against misleading hearers doesn't look like it can explain a distinctively epistemic wrongness. Therefore, Pagin doesn't explain phenomena Williamson takes himself to be explaining.

At this point, Pagin could disagree about the phenomena, and claim that the wrongness of asserting a lottery proposition is not distinctively epistemic, but I won't pursue this approach here. I agree with Williamson that some assertions are wrong in a distinctively epistemic fashion. Furthermore, granting Williamson this allows a more dialectically satisfying response.

\subsection{Williams: norms on assertion are reducible to norms on action and norms on belief}

Bernard Williams responds to Williamson's arguments for knowledge norm by claiming there are two ways of 'doubting' or 'objecting' to someone's assertion. Either one doubts that the person's assertion is true; or one doubts whether what the person asserted is really their belief. But Williams goes on to claim that 'These doubts or objections do not imply any distinct norm, involving the idea of authority, which is attached to the speech-act of assertion. The objections that the supposed expression of belief is insincere, or that the belief expressed may not be true, are appropriate simply in virtue of the nature of assertion as the direct expression of belief' (2002, p. 78).

These two 'objections' stem from Williams' psychological account of assertion: 
(a) A psychological feature of assertion: A asserts that $\mathrm{p}$ when: A utters a sentence ' $\mathrm{S}$ ', where 'S' means $\mathrm{p}$, in doing which either A expresses their belief that $\mathrm{p}$, or A represent themselves as believing that $\mathrm{p}$ (Williams, 2002, p. 74). ${ }^{4}$

This account's disjunctive structure gives us two ways to object to assertion. If it's an expression of belief, the belief expressed can be objected to as false. If it's a representation of belief, the action can be objected to as misleading. In Williams' terms, the asserter can fall short either with regards to the virtue of accuracy or the virtue of sincerity. In effect, we have the following norms:

(b) Non-assertion-specific norms: One ought not to have false beliefs; One ought not deceive.

And these norms explain our criticism of assertions without appeal to a sui generis norm on assertion.

How does William's response fare? It improves on Pagin's response in one respect, because one of Williams' two ways of 'objecting' to an assertion looks distinctively epistemic. 'Objecting' to an assertion because the belief expressed is not true does look like a distinctively epistemic objection, as it's commonly assumed that truth is an epistemic value. ${ }^{5}$

Nevertheless, Williams' account also fails because, like Pagin, he has misidentified the phenomena to be explained, though in a rather different way. The problem is that the epistemic objection Williams claims one can make of an assertion - the objection that the belief expressed is not true - is not an objection to an assertion; it's only an objection to a belief. This means that it can't explain the relevant phenomena. Williamson takes himself to be explaining the wrongness of assertions, not the wrongness of beliefs expressed through assertion. As Williams recognizes (2002, p. 76), this kind of wrongness is at issue when one says 'You shouldn't have said that if you didn't know it [or: if it was false]'. If what is at fault is the asserter's false belief, or a belief which doesn't amount to knowledge, then we haven't found anything wrong with the assertion itself, which was what was to be explained (cf. Williamson, 1996, pp. 512-14).

\footnotetext{
${ }^{4}$ Williams' second disjunct actually is 'intends that the hearer comes to believe that the speaker believes that p', but for simplicity I've made it more like the psychological feature Pagin appeals to.

5 Truth might not be the fundamental epistemic value, but Williams' account can easily be amended to account for this. We can thus set aside the fact that Williams - because he only discusses objecting to assertions by pointing out they are not true - fails to explain the wrongness of asserting, say, a lottery proposition. His account could explain such wrongness if we also supposed that one can criticize a belief if it doesn't amount to knowledge.
} 


\subsection{Hindriks and Bach: norms on assertion are reducible to the combination of norms on action and norms on belief}

A third version of the no-norm-of-assertion strategy is to appeal to the combination of norms on action and norms on belief. The following derivation, given independently by Frank Hindriks (2007) and Kent Bach (2008, pp. 76-77), appeals to the combination of a knowledge norm on belief and a sincerity norm on assertion:

(1) One must: believe that $\mathrm{p}$ only if one knows that $\mathrm{p}$.

(2) One must: assert that $\mathrm{p}$ only if one believes that $\mathrm{p}$.

(3) Therefore, one must: assert that $\mathrm{p}$ only if one knows that $\mathrm{p}$.

This derivation might seem to avoid the flaws in Pagin's and Williams' accounts, but it faces a further objection. Specifically, Brian Ball has pointed out that the derivation equivocates between an epistemic 'must' in (1) and a moral 'must' in (2) (2014; for further defence, see Simion, 2019, sec. 3.1).

In response to Ball, Hindriks and Barteld Kooi point out that a term having two senses does not by itself suffice for the fallacy of equivocation. To truly equivocate, an argument needs to trade off the different senses illegitimately. And Hindriks and Kooi claim that Ball has not shown that their derivation does this (2014, pp. 90-91). While Hindriks and Kooi are correct about what equivocation requires, it doesn't seem correct that the burden of proof is on their opponents in the way they suggest. The alleged equivocation is that because of the different kinds of normativity embodied in the relevant 'musts' - i.e. epistemic in (1); moral in (2) - it doesn't follow from (1) and (2) that one 'must' assert p only if one knows that $\mathrm{p}$ in any one sense of 'must'. For that to follow, we would need auxiliary assumptions about the relationship between epistemic and moral normativity (just as if someone gave a similar derivation with a legal 'must' in one premise and a moral 'must' in another, we would need auxiliary assumptions about the relation between legal and moral normativity to see what follows). Given this, the burden of proof is plausibly on Hindriks and Kooi to show that their derivation does not equivocate. And the account I will offer certainly makes no such equivocation, as it will only appeal to a single (epistemic) norm on action.

\section{My account: norms on assertion are reducible to epistemic norms on action}

The accounts put forward by Pagin and Williams both failed to account for the phenomena that Williamson is trying to explain. Pagin fails to identify norms that could explain the epistemic wrongness of certain assertions. Williams fails to identify norms that could explain the wrongness of assertions. These two failures point towards a successful version of the nonorm-on-assertion strategy, one which appeals to a distinctively epistemic norm on action, i.e. 
a norm that one ought not to act on epistemically faulty beliefs. This norm can explain why assertions themselves are wrong in a distinctively epistemic fashion without appeal to sui generis norm of assertion.

This version of the no-norm-of-assertion strategy appeals to the combination of:

(a) A psychological feature of assertion: If A sincerely asserts that $\mathrm{p}$, in doing so A acts on the belief that $\mathrm{p}$ (at least for all assertions where epistemic criticism is appropriate).

(b) A non-assertion-specific norm: One ought not to act on epistemically faulty beliefs.

Let's unpack each of these claims in turn.

My first claim is that making a sincere assertion that $\mathrm{p}$ involves acting on the belief that $\mathrm{p}$. We can see why this is the case by initially highlighting how assertions are intentional actions done for reasons. There are a variety of ways of understanding what it is to act for a reason, though I'll appeal to Davidson's account which analyses this in terms of motivation by a 'primary reason', i.e. a desire and a means-end belief that jointly rationalize and motivate the action (Davidson, 1963, p. 686). A primary reason can typically be revealed by asking someone why they are doing something (or why they did something), as their response will typically either state or suggest the relevant primary reason. For example, if I ask you why you're going to the shops and you say 'I want some butter, and there's butter in the shops', you make manifest your primary reason for action, i.e. a desire to get some butter, and a belief that you can get butter by going to the shops.

Now not everyone agrees that motivating reasons for action are mental states. Others would say I'm motivated by the fact that I can get butter in the shops and the goal of getting butter (e.g. Alvarez, 2010, chaps. 4-5). I'll assume for simplicity that the motivation of action is to be understood in terms of Davidsonian primary reasons, though this doesn't affect my argument. ${ }^{6}$

But if the Davidsonian picture is assumed, it's clear that assertions are motivated by primary reasons just like any other intentional action. For example, say a tourist asks you where the station is, and in response you say 'The station is round the corner'. If you're asked why you said that, a natural response (assuming your assertion is sincere) would be

\footnotetext{
${ }^{6}$ My version of the no-norm-of assertion strategy could still be given, mutatis mutandis, if motivating reasons are facts. If motivating reasons are facts, epistemic criticism will still be appropriate if someone takes a mistaken course of action because they hold an epistemically faulty belief. The defender of the fact-based view will just deny this belief is the agent's reason for acting (for a discussion of how the fact-based view should understand an agent's reason in such cases, see Alvarez, 2018, pp. 3301-4). And if epistemic criticism of action is appropriate in such a case, a version of my account can be given.
} 
something like 'She asked me where the station is, and the station is round the corner'. We can understand this in terms of the same kind of belief-desire pair motivating the assertion: a desire to tell her where the station is and the means-end belief that you can do this by telling her that the station is round the corner.

This doesn't yet get us the claim that the assertion involves acting on a belief with the content asserted - i.e. a belief that the station is round the corner - but it's a short step to that conclusion. This is because the means-end belief that you can tell the stranger where the station is by telling her that it is round the corner is itself based on the belief that the station is round the corner. And because of this, it is fitting to say that your assertion that the station is round the corner is, at least in part, motivated by a belief with the content asserted; this belief is among your reasons for action.

Now, of course, there may be other things you might cite as your reasons in this case. You might instead say 'She wanted to know where the station is, and I wanted to help', or 'She asked me directions', or even 'A good citizen helps out those in need'. In such a case, these different answers are not really in competition, and which will be given will often depend on what the questioner is after. The crucial thing is that however we understand your reasons, it's certain that among those reasons will be a belief that the station is round the corner. This is because, given what you are doing - i.e. giving directions -, and given you're doing this honestly and sincerely, we won't be able to make rational sense of your assertion unless we make reference at some stage to a belief that the station is round the corner.

Furthermore, while this is just one example, it's plausible that we will be able to say the same about all other assertions where the distinctive kind of epistemic criticism discussed in the norm-of-assertion literature is appropriate. All such assertions will plausibly involve acting on a belief with the content asserted. Now in the example I've given, you're doing something by asserting that the station is round the corner - i.e. you're giving directions - which meant that a belief that the station is round the corner is among your reasons for action. Now there are many other things one can do by making an assertion, where, if the assertion is sincere, a belief with the content asserted will be among your reasons for action. For example, in making an assertion, you could be giving financial advice, warning your child, arguing with your neighbour, instructing a class, or giving testimony in court. In all these cases, if the assertion is sincere, it will be motivated in part by a belief with the content asserted. My suggestion that in all cases of assertion where epistemic criticism looks appropriate, we'll be able to find something similar which you're doing by making the assertion that will mean that a belief with the content asserted is among your reasons for making the assertion.

The caveat is important. I am only claiming that this will be true of assertions of which epistemic criticism is appropriate. I'm not claiming that all assertions will be partly motivated by a belief with the content asserted. Firstly, and obviously, I'm not claiming this is true of insincere assertions. But this isn't problematic because, as I'll argue in the next section, epistemic criticism looks out of place with insincere assertions. Secondly, I'm not 
even claiming that all sincere assertions are partly motivated by a belief with the content asserted. That claim may be true, but I'm not relying on it. I'm making the weaker claim that if epistemic criticism of an assertion is appropriate - i.e. if it's appropriate to say that someone isn't in a good enough epistemic position to assert what they did - then they will be doing something by making that assertion, and that action will be partly motivated by a belief with the content asserted.

Let's now move on the second element of my account, a norm that one shouldn't act on epistemically faulty beliefs. It seems uncontroversial that actions are subject to some norm of this kind. We can see this by recognising two ways we can criticize an action, which again can be illustrated by reference to the primary reason that motivated the action. On the one hand, we can criticize the action by focusing on the desires or goals that led to it; on the other hand, we can criticize the action by focusing on the beliefs that led to it.

We can illustrate these two kinds of criticism with an example from recent British politics. In April 2017, the Conservative Prime Minister Theresa May called an early general election. May's stated aim was that an increased majority would 'strengthen her hand' for the upcoming negotiations about the UK's departure from the European Union. The Conservatives lost their overall majority in the election, and had to form a minority government. One could criticize May's calling of a snap election in two ways:

'Theresa, you shouldn't have called a snap election. You didn't need an increased majority to strengthen your hand for Brexit negotiations.'

'Theresa, you shouldn't have called a snap election. You didn't have sufficient evidence that you would increase your majority.'

The first criticism focuses on the desire or goal that led to May's action (the desire to strengthen her hand for Brexit negotiations). The second focuses on the belief that led to it (the belief that she would increase her majority). This second kind of criticism can be prudential; we could object that May didn't have sufficient evidence that a snap election was a good way to achieve her goals. But this second kind of criticism can also be moral, e.g. we could add to our second criticism of May 'You negligently led the country into uncertainty'.

This second kind of criticism - whether prudential or moral - is an epistemically orientated criticism of an action. It is not just criticism of the belief that led to the action, but criticism of action itself which focuses on the belief that led to it. If the above criticism is warranted, it's not appropriate to say 'She shouldn't have thought that, but given that she did, we can't blame her for doing what she did'. Rather, it is criticism of the action itselfcalling a snap election - an action we criticize as careless or negligent.

The fact that this is criticism of action and not just criticism of belief can be highlighted by the fact that we treat people who act on unjustified beliefs differently from those who merely hold unjustified beliefs without acting. For example, someone who acts on an unreasonable belief that someone is below the age of consent - e.g. someone who 
unreasonably believes their sexual partner is over the age of consent when they are not can, in English law, be prosecuted for a sexual offence. ${ }^{7}$ Someone who merely has the unreasonable belief commits no offence. And the same is true for all other cases of negligence in criminal and tort law; you need to act on the faulty belief in order for there to be a case against you. And this surely tracks our common-sense moral thinking. Acting on an unreasonable belief is a different and more serious matter than merely having a such a belief. This suggests that the kind of criticism I've outlined above is not just criticism of the belief that led to the action - otherwise acting on the belief shouldn't make a difference - but is a distinct, epistemically-orientated criticism of action.

The fact that we criticize actions in this way indicates that there is what I'll call an 'epistemic norm on action', i.e. a norm that one ought not act on epistemically faulty beliefs. Other things might be called 'epistemic norms on action', which should be distinguished from this. For example, there might be things we ought to $d o-$ such as gathering evidence, doing experiments, etc. - to satisfy purely theoretical, epistemic aims. This is not what I mean by 'epistemic norm on action'. My claim is that part of our moral and prudential appraisal of actions is distinctively epistemic in that it focuses on whether the beliefs that led to the action were epistemically faulty.

That suffices to outline the two elements of my account - the fact that assertion is an action and the fact that there is some epistemic norm on action. These two facts, I claim, can explain the phenomenon Williamson appeals to - the intuitive wrongness of certain assertions. This means this this phenomenon is not best explained by a sui generis norm that is constitutive of assertion.

I'll explain why starting with my tourist example, before moving on to the assertions Williamson discusses. In my example, your assertion that station is round the corner was jointly motivated by a desire to tell the tourist where the station is and the belief that you can do this by telling her that the station is round the corner, which was in turn based on the belief that the station is round the comer. Given this, one can criticize the action - the assertion - by focusing on either the beliefs or desires that motivated it. On the one hand, we can criticize you, and say 'You shouldn't have said that', on the basis that the station isn't round the corner, or you don't know that it is, or you don't have good evidence that it is. On the other hand, we could criticize you, and say 'You shouldn't have said that', on the grounds that the 'tourist' was clearly a terrorist seeking to blow up the station. Because an assertion is an intentional action, we can criticize it by appealing to two different kinds of non-assertion specific norms, a) a norm that one shouldn't act on epistemically faulty beliefs, and b) a norm that one shouldn't help terrorists.

We can now return to Williamson, who claims KNOWLEDGE NORM best explains:

\footnotetext{
7 The Sexual Offences Act 2003, §§9(c)(i), 10(c)(i).
} 
(a) The wrongness of asserting lottery propositions, e.g. 'My ticket didn't win'.

(b) The wrongness of asserting a kind of Moore-paradoxical propositions, those of the form 'p, but I don't know that p'.

(c) Why we respond to assertions by saying 'How do you know that?'.

As I've said, I'm claiming only sincere assertions of these propositions exhibit a distinctive epistemic wrongness, and any wrongness in insincerely asserting these propositions should be explained by practical norms against deception. I'll defend this latter claim in the next section, but let's restrict our attention to sincere assertion for now.

If the assertions in question are sincere, then the three cases Williamson appeals to can be explained by an epistemic norm on action, i.e. a norm that one shouldn't act on epistemically faulty beliefs. However, this norm is deliberately generic, and in order to explain these cases, we need to unpack the sense of 'epistemically faulty' which figures in it. So let's for the moment assume the following norm which unpacks this in terms of knowledge:

KNOWLEDGE NORM ON ACTION: One ought not to act on a belief that $\mathrm{p}$ unless one knows that p (Hawthorne, 2004, pp. 29-30; Hawthorne and Stanley, 2008).

If we assume this epistemic norm on action, the wrongness of the assertions Williamson discusses is easily explained, given what I've said about motivation.

Let's start with (a) and (b). If what I've said so far is right, for any sincere assertion of a lottery proposition or a proposition of the form 'p, but I don't know that p' where epistemic criticism is appropriate - i.e. any case where the speaker can be criticized for not being a good enough epistemic position to assert what they did - the speaker will be doing something in part motivated by a belief with the content asserted. Given this, such assertions of either of these kinds of propositions will violate KNOWLEDGE NORM ON ACTION. One will be doing something that is careless or negligent. So KNOWLEDGE NORM ON ACTION can explain the wrongness of these assertions. ${ }^{8}$

We can say much the same about (c). Responding to assertions by saying 'How do you know that?' presupposes that the speaker knows what they assert, and Williamson claimed a knowledge norm on assertion can explain why this expectation is legitimate. If this is correct, then KNOWLEDGE NORM ON ACTION would be equally capable of explaining why this expectation is legitimate, if the assertion in question is sincere.

\footnotetext{
${ }^{8}$ One may claim that it's not always negligent to act on a belief that doesn't constitute knowledge - by, say, selling one's ticket if one is offered a decent price - but maintain that it's still wrong to assert the lottery proposition. This does not undermine my account, however, as acting on the belief (by selling the ticket) and asserting the lottery proposition are two different ways of acting on a belief, and there is more to gain in relation to one than in relation to another (I discuss such cases further in §6.2).
} 
A knowledge norm on action can therefore explain these three cases just as well as a knowledge norm on assertion. However, my fundamental claim can be generalized further, and also applies to alternative norms on assertion, like the following:

TRUTH NORM: One ought not to assert $\mathrm{p}$ unless $\mathrm{p}$ is true.

JUSTIFICATION NORM: One ought not to assert that $\mathrm{p}$ unless one is justified in believing that $\mathrm{p}$.

You might defend these alternative norms because you don't share Williamson's intuitions, or because other cases favour these norms over a knowledge norm. Or you might you agree with Williamson's intuitions, but think, contra Williamson, that these intuitions are in fact better explained by a truth (Weiner, 2005) or justification norm (Kvanvig, 2009). My fundamental point - that the wrongness of assertions can be explained by norms on action - still holds. Suppose Williamson's opponents are correct, and the wrongness of assertions should be explained by reference to truth or justification rather than knowledge. My claim is that this explanation should be done in terms of alternative norms on action, such as:

TRUTH NORM ON ACTION: One ought not to act on a belief that $\mathrm{p}$ unless $\mathrm{p}$ is true.

JUSTIFICATION NORM ON ACTION: One ought not to act on a belief that $\mathrm{p}$ unless one is justified in believing that $\mathrm{p}$.

These norms on action can provide the requisite explanation because any sincere assertion that $\mathrm{p}$ which it looks appropriate to criticize epistemically will be motivated by a belief that p. Therefore, if the wrongness of assertions can be explained by alternative norm on assertions, then it also can be explained by these alternative norms on action. Any sincere assertion that violates a truth norm on assertion will violate the corresponding truth norm on action, and the same will be the case for any putative norm on assertion.

This is what also allows us to transpose the moves in the norm-on-assertion debate to the question of what epistemic requirements there are on action. My aim in this paper is not to take a side in this first-order debate. My claim is that whatever side we take in this first-order debate, the explanation can be done in terms of epistemic norms on action rather than sui generis norms on assertion. And if this is the case, the debate on the norms of assertion does not - and could not given the kind of phenomena appealed to - show that there is a sui generis norm on assertion.

\subsection{What about insincere assertions?}

I've said throughout that I will treat insincere assertions differently, and that I would only explain how sincere assertions can be wrong in a distinctively epistemic fashion. In other words, on my account, it's only to a sincere assertion that one can object to by saying 'You shouldn't have said that if you didn't know it' (or with some alternative epistemic criticism). 
This doesn't mean that insincere assertions can't be wrong, it just means we have to explain their wrongness in other terms, for example by practical norms against deception.

The defender of a sui generis norm on assertion may object to this point. They may simply claim it's intuitively inappropriate to assert that $\mathrm{p}$ if one does not know $\mathrm{p}$, whether or not one is sincere. They also may claim that this means that a sui generis norm on assertion has an advantage over my account with respect to simplicity, in that it provides a unified explanation of sincere and insincere assertions alike.

We can say two things in response. Firstly, with regards to simplicity, it's not really clear that an explanation appealing to a sui generis norm on assertion is simpler than my account. This is because such an explanation appeals to a distinctive and sui generis norm on assertion, whereas my account just appeals to norms on action we have independent reason to believe in. In this respect, my account is simpler.

Secondly, and more importantly, it doesn't actually look like insincere assertions manifest the distinctively epistemic inappropriateness Williamson appeals to a norm on assertion in order to explain. This also answers the version of the objection which appeals simplicity, as it means that the inappropriateness of sincere and insincere assertions do not in fact demand a unified explanation.

Treating insincere assertions differently would be problematic if insincere assertions of the relevant propositions - lottery propositions and propositions of the form 'p, but I don't believe that p' - did indeed look wrong or inappropriate in the distinctively epistemic manner discussed by the norm-on-assertion literature. But this doesn't look like it's the case. Insincere assertions of these propositions do not look epistemically wrong. Say you assert 'My ticket didn't win' to someone who's pressuring you to hand over your ticket, with a view towards making them look elsewhere. Say you say 'I was born in England, but I don't know that', not because you think it's true, but in order to make it seem like you have an annoying counterexample to a philosopher's theory. In these cases, it looks out of place to say 'You shouldn't have said that if you didn't know it'. Furthermore, in the case of outright lies this criticism looks very strange. Surely if someone's lying, then whether or not they know what they are saying is true seems irrelevant, and surely the reason why they should (or should not) be criticized for telling the lie are to be found elsewhere.

Further support is provided by cases when one should tell a lie. White lies - minor lies which save hurt or offence - are often such cases. Lying in cases where telling the truth would enable others' wrongdoing are definitely such cases. An example of this second kind is lying to a Nazi by saying you are not hiding Jews under your floorboards when you in fact are. This kind of case, more often discussed in moral philosophy, is appealed to as an objection to Williamson by Hindriks $(2007,402)$. The problem is that if there is a sui generis norm on assertion - whether a knowledge, truth, or justification norm - then by lying to the Nazis you have violated that norm and your assertion is inappropriate in a distinctively epistemic fashion. This is highly implausible. It sounds very strange to say that such an assertion is epistemically inappropriate or, to in the way that Williamson puts it, that you lack the 'epistemic authority' to assert that you are not hiding Jews under the floorboards. 
There is a response Williamson would likely give here. This is to claim that the knowledge on norm on assertion is only a pro tanto obligation, one that can be trumped by other more serious obligations, and that in the Nazi case the knowledge norm is trumped by more important considerations. ${ }^{9}$ This response is given by Ball:

[] $\mathrm{t}$ is always pro tanto wrong to lie, even if it is not ultimately wrong, all things considered. On the assumption that assertion is governed by an unrestricted knowledge norm we have the resources at our disposal to explain this fact - that it violates this norm, we may say, counts against an act morally, but without any such unrestricted norm in place, it is unclear how this fact can be accounted for, if at all. (Ball, 2014, p. 81)

This response is not plausible. Even if we grant that lying is always pro tanto wrong, a knowledge norm doesn't provide a good explanation of that. It mischaracterizes the nature of the wrongdoing in lying, because it makes the underlying wrongdoing primarily epistemic - i.e. on this picture, lying would wrong because it involves asserting what you're not in a good enough epistemic position to assert. This surely mischaracterizes the wrong in lying. Even if we grant that you do something pro tanto wrong in lying to the Nazi, it's not plausible that the wrong is asserting something you're not in good enough epistemic position to assert. The fact that you don't know that you are not hiding Jews under your floorboards just looks irrelevant to whether or not you should say that you are. If there is any pro tanto wrong in lying to the Nazi, it's surely the wrong of deception. The fact that a course of action is deceptive plausibly always counts against it to at least some degree, and thus deception plausibly is a pro tanto wrong. But we can say all this without appealing to any sui generis norm on assertion.

The knowledge norm being a pro tanto obligation does not, therefore, provide an answer to my key claim, that the distinctively epistemic criticism discussed in the norm-onassertion literature looks out of place with insincere assertions. This is because insincerely asserting what you don't know just doesn't look epistemically wrong, even pro tanto. Given this, the fact that my account entails that epistemic criticism is out of place with insincere assertions is actually a point in its favour.

\footnotetext{
${ }^{9}$ Williamson would likely respond in this way, as Hindriks points out (2007, p. 402), as he claims that cases where urgency requires you to say something you know you don't know 'do not show that the knowledge rule is not the rule of assertion; they merely show that it can be overridden by other norms not specific to assertion' (Williamson, 1996, p. 508).
} 


\section{Objections and Replies}

\subsection{Epistemically (in)appropriate assertions without belief?}

My account claims that epistemic propriety only applies to sincere assertions - i.e. when one believes what one asserts. If I'm right, then there shouldn't be any case of epistemically (in)appropriate assertion without belief.

Jennifer Lackey claims there are such cases. Her putative example, originally put forward as a counterexample to a knowledge norm on assertion, is a creationist teacher, Stella, who does not believe in evolutionary theory because of her Christian faith. Despite her faith, however, Stella regards her duty as a teacher to present what is best supported by the evidence, which she admits includes the truth of evolutionary theory. As a result, she asserts in her biology class 'Modern day Homo sapiens evolved from Homo erectus' (Lackey, 2007, p. 599). Lackey claims that Stella's assertion is 'evidentially impeccable' (2007, p. 600). If Lackey is correct, this is a case of epistemically appropriate assertion not motivated by a belief with the content asserted.

I don't think Lackey's example is problematic. There are two points to make in response to it. Firstly, it looks quite plausible to accept it's a case of appropriate assertion, but deny, pace Lackey, that it's a case of epistemically appropriate assertion. The appropriateness of the assertion might instead stem from practical or moral requirements on being an educator, and the fact that Lackey mentions Stella's conception of her duties in setting up the case is revealing in this respect (cf. Reynolds, 2017, pp. 153-54).

Secondly, while my account can't say Stella's assertion is epistemically appropriate, it can explain why some of her alternative options would be epistemically inappropriate. This is because if she either asserts that evolutionary theory is false or omits teaching evolutionary theory on the basis of her creationist beliefs, that would be acting on an epistemically faulty belief, and would violate the epistemic norm on action.

Therefore, we can say that our positive assessment of Stella stems from the combination of Stella's morally admirable commitment to her duties as teacher together with the fact that she avoids potential epistemic inappropriateness. That seems plausible, given it's hardly an uncontroversial core case of epistemically appropriate assertion.

\subsection{Arguments against 'commonality'}

I've claimed that the epistemic appropriateness of assertions and actions have the same underlying explanation. Jessica Brown has called this claim 'commonality'. I'll now answer some arguments against this claim: three from Brown, and a fourth from Mona Simion.

Brown's first two arguments are directed against the claim an epistemic norm on action can explain the epistemic propriety of actions simply because assertions are actions. Brown's first objection to this explanation is that asserting that $\mathrm{p}$ is only one way to act on p. One may act on $\mathrm{p}$ by asserting 'p' sincerely. One may act on $\mathrm{p}$ by lying and asserting 'not-p' if one has the goal of misleading one's audience. A misleading assertion, Brown 
claims, may be an epistemically appropriate action (2012, pp. 131-34). This is correct, but unproblematic for my account, which treats sincere and insincere assertions differently; only sincere assertions, I've argued, are ones where there is epistemic propriety to be explained.

Brown's second objection is that some speech acts have epistemic requirements that differ from assertion's, a point made by Williamson (1996, p. 496). Some speech acts have weaker requirements than assertion. Brown's examples are surmising that $\mathrm{p}$ and asking whether p. Other speech acts have stronger requirements, such as swearing that p. Brown takes this to show that the fact that an assertion is an action does not by itself explain the epistemic appropriateness of assertions (2012, p. 131).

It is again correct that other speech acts are appropriate in different circumstances from assertion. However, my account can deal with this, largely because it appeals to how assertions are motivated.

Let's start with surmising and asking. Surmising looks like it won't be motivated by a belief that $\mathrm{p}$, but by some other state, such as a belief that $\mathrm{p}$ might be the case, or a suspicion that $\mathrm{p}$ is the case. Likewise, typical instances of asking whether $\mathrm{p}$ are requests for information one doesn't already have, and so won't be motivated by a belief that p. A fortiori, they won't be instances of acting on an epistemically faulty belief. Some cases of asking whether p may be motivated by a belief that p. For example, a teacher may ask a student whether Kennedy was the last American president to be assassinated, when the teacher knows he was, in order to test the student's knowledge. This is a case of asking whether $\mathrm{p}$ motivated by a belief that $\mathrm{p}$, but it's not problematic for my account. If by asking whether $\mathrm{p}$, you're testing whether a student knows that $\mathrm{p}$, that's something you shouldn't do unless you know that $p$. What is needed to undermine my account is a case of asking whether $p$ which is both a) plausibly motivated by a belief that $\mathrm{p}$, and b) is not a case where one shouldn't ask whether $\mathrm{p}$ if one doesn't meet the relevant epistemic requirements on action. It's unclear that there are such cases.

Let's now move on to swearing. The first thing we can say is that many instances of swearing that $\mathrm{p}$ will not motivated by a mere belief that $\mathrm{p}$, but by a stronger doxastic attitude like being sure or certain that $p$. If that's the case, then any stronger epistemic requirements can stem from acting on the stronger attitude. However, it doesn't look like all instances of swearing will be motivated by a stronger doxastic attitude. Consider a boy who's trying to inform the townsfolk about an approaching wolf, but none of them believe him because he has a history of lying. Such a boy might swear that a wolf is approaching, not because he's sure or certain that there is a wolf, but just in order to try and improve his chances of being believed. This looks like a case of swearing motivated by mere belief.

In response, I think we should dispute Williamson's initial claim that swearing has a higher epistemic requirement than assertion. The requirements on swearing that p certainly are more stringent in the sense that the audience has a greater right of complaint if $p$ turns out to be false. But we shouldn't automatically conclude that this stems from a higher epistemic requirement. Compare the parallel case of promising. If I promise you that I'll 
make dinner, you have a greater right of complaint if I fail to make dinner that if I merely asserted that I would. But this doesn't stem from promising requiring me to be in a better epistemic position with regards to whether I'll make dinner; rather, it's because promising, in being the normative power that it is, involves granting you a greater right of complaint. It seems plausible that swearing is somewhat similar to promising in this regard. Swearing that p plausibly is something like staking one's reputation on p's being the case - think of the phenomena of swearing 'before God' or 'on my mother's life'. If this is correct, cases of swearing motivated by belief are unproblematic for my account. The fact that swearing is staking one's reputation on p's being the case can explain why the audience has a greater right of complaint on its own, and without appealing to swearing having distinctively epistemic requirements greater than assertion's.

Brown's third and final argument against commonality is that high and low stakes, she claims, can affect the epistemic appropriateness of assertion and action differently. Brown gives a series of examples to support this, but it will suffice to discuss one. Brown gives the case of Sally, who's waiting for a train home. Express and non-express trains leave from the platform she's waiting at, and while she'd prefer an express train, it wouldn't be a disaster if she got a non-express. On the basis of checking the timetable, she believes the next train is an express. Brown claims that Sally is in a good enough position to act on the belief that the next train is an express, but need not be in a good enough position to assert that it is. In particular, Brown claims that if a stranger explains to her it is crucial for him to get an express, Sally does not look like she's in a good enough epistemic position to assert that the next train is an express (Brown, 2012, p. 140). This case, Brown claims, shows the epistemic appropriateness of acting on $\mathrm{p}$ may depend on what is at stake for the agent, whereas the epistemic appropriateness of asserting that $\mathrm{p}$ may depend on what is at stake for the audience. This would undermine my account as it would mean the epistemic standards on action and (sincere) assertion don't march in step.

Such cases do not undermine my account. We can accept that Sally's action - of getting on the train - is epistemically appropriate even though her assertion - that the next train is an express - is not without denying that the standards of epistemically appropriate assertion stem from norms on action. This is because the action of getting on the train and the action of asserting that the next train is an express train are different actions, and more is at stake in relation to one action than in relation to the other. Because more is at stake in relation to Sally's action of asserting that the next train is an express, because the stranger really needs to get an express, the epistemic standards on that action will be higher. Because less is at stake in relation to Sally's action of getting the train, because it doesn't matter as much to Sally, the epistemic standards on that action will be lower. And the epistemic standards on the assertion need not always be higher; if the roles were reversed and Sally really needs to get the express but the stranger does not, then she may be in a position to assert, but not to get on the train. The important point is that these are just cases in which there are two different ways of acting on a belief, and more is at stake in relation to one than the other. Such cases do not undermine my account. If anything, they support it. 
Let's now move on to Simion's objection to commonality. Simion claims that norms on assertion cannot be explained by a norm against acting on epistemic faulty beliefs, because the latter is not genuinely epistemic. Simion claims it is 'pretty obvious' that a norm against asserting what you don't know is 'a genuinely epistemic norm', but a norm against acting on epistemically faulty beliefs, she claims, is merely a norm 'featuring epistemic content' such as a norm against dancing to songs you don't know (2019, p. 1960). If a norm against acting on epistemic faulty beliefs isn't a genuinely epistemic norm, Simion claims, it can't explain a genuinely epistemic norm on assertion.

Simion's objection can be answered by recasting my key claim in her terminology. I have argued that the supposed evidence for a sui generis norm on assertion - the intuitive wrongness of assertions - doesn't require a genuinely epistemic norm to explain it; a norm featuring epistemic content suffices. If this is the case, then, pace Simion, it's not obvious that assertion norms are genuinely epistemic norms as she understands this. Now Simion does argue for the claim that norms on assertion are genuinely epistemic norms, on the grounds that assertion, she claims, has a distinctively epistemic function (2019, sec. 4). And while I can't go into those arguments here for want of space, I don't need to in this context. This is because if one has to provide arguments that the wrongness of assertions does not stem from a norm that merely features epistemic content, that vindicates my key claim: independent argument is required before the intuitive wrongness of assertions provides any support for a specific sui generis norm on assertion.

\section{Conclusion}

Our practices of criticizing and challenging each other's assertions do not, therefore, support a sui generis norm constitutive of assertion. Is there any other good argument for such a norm? I haven't argued that there isn't. But my suggestion would be not to bother trying to give one. This is because, somewhat counterintuitively, a sui generis norm is not really central to the issues discussed in the norm-of-assertion literature. Arguments about whether assertion is subject to a knowledge, truth, or justification norm can largely be transposed to the debate about the epistemic requirements on action. We can and should forget about a sui generis norm of assertion. Doing so results in a more accurate picture of how what we should and shouldn't say falls within - and relates to - the more general category of what we should and shouldn't do. ${ }^{10}$

\footnotetext{
10 I would like to thank to Bernard Salow, Sophie Archer, Lucy Campbell, Claire Field, Simon-Pierre Chevarie-Cossette, Max Kiener, and an anonymous reviewer from Philosophy for comments on previous drafts. I am also grateful to audiences at Cambridge, Southampton, and Birkbeck, as well as to Nikhil Krishnan, Sophie Archer, and Lucy Campbell, for helpful discussion of the ideas in this paper.
} 


\section{References}

Alvarez, Maria, Kinds of Reasons: An Essay in the Philosophy of Action (Oxford: Oxford University Press, 2010).

Reasons for Action, Acting for Reasons, and Rationality', Synthese, 195:8 (2018), 3293-3310.

Bach, Kent, 'Applying Pragmatics to Epistemology', Philosophical Issues 18:1 (2008), 68-88.

Ball, Brian, 'Deriving the Norm of Assertion', Fournal of Philosophical Research, 39 (2014), 75-85.

Brown, Jessica, 'Assertion and Practical Reasoning: Common or Divergent Epistemic Standards?', Philosophy and Phenomenological Research, 8:1 (2012), 123-57.

Brown, Jessica, and Herman Cappelen, 'Assertion: An Introduction and Overview', in Assertion: New Philosophical Essays, edited by Brown and Cappelen (Oxford: Oxford University Press, 2011), $1-16$.

Cappelen, Herman, 'Against Assertion', in Assertion: New Philosophical Essays, edited by Brown and Cappelen (Oxford: Oxford University Press, 2011), 21-47,.

Davidson, Donald, 'Actions, Reasons, and Causes', The Journal of Philosophy, 60:23 (1963), 685-700.

DeRose, Keith, 'Assertion, Knowledge, and Context', The Philosophical Reviere, 111:2 (2002), 167-203.

Douven, Igor, 'Assertion, Knowledge, and Rational Credibility', The Philosophical Review, 115:4 (2006), 449-85.

Hawthorne, John, Knoweledge and Lotteries, (Oxford: Open University Press, 2004).

Hawthorne, John, and Jason Stanley, 'Knowledge and Action', The Journal of Philosophy, 105:10 (2008), 571-590.

Hindriks, Frank, 'The Status of the Knowledge Account of Assertion', Linguistics and Philosophy, 30:3 (2007), 393-406.

Hindriks, Frank, and Barteld Kooi, 'Reaffirming the Status of the Knowledge Account of Assertion', Fournal of Philosophical Research, 39 (2014), 87-92.

Kvanvig, Jonathan, 'Assertion, Knowledge, and Lotteries', in Williamson on Knowledge, edited by Duncan Pritchard and Patrick Greenough (Oxford: Oxford University Press. 2009), 140160.

Lackey, Jennifer, 'Norms of Assertion', Noûs, 41:4 (2007), 594-626.

Pagin, Peter, 'Problems with Norms of Assertion', Philosophy and Phenomenological Research, 93:1 (2016), 178-207.

Reynolds, Stephen, Knoweledge as Acceptable Testimony (Cambridge: Cambridge University Press, 2017).

Simion, Mona, 'Saying and Believing: The Norm Commonality Assumption', Philosophical Studies, 176:8 (2019), 1951-66.

Weiner, Matthew, 'Must We Know What We Say?', The Philosophical Review, 114:2 (2005), 227-251.

Whiting, Daniel, 'Stick to the Facts: On the Norms of Assertion', Erkenntnis, 78:4 (2013), 847-867.

Williams, Bernard, Truth and Truthfulness: An Essay in Genealogy (Princeton: Princeton University Press, 2002).

Williamson, Timothy, 'Knowing and Asserting', Philosophical Review, 105:4 (1996), 489-523.

ALEXANDER GREENBERG (a.greenberg@ucl.ac.uk) is a Leverhulme Early Career Fellow in the Department of the Philosophy at University College London. His main interests are in the intersection of epistemology, philosophy of mind, and the philosophy of the criminal law. His other published papers include 'Epistemic Responsibility and Criminal Negligence' in Criminal Law and Philosophy and 'Should I believe all the truths?' in Synthese. For more information, see his website: https://alexandergreenberg.github.io. 